\title{
Investigating the barriers on media privatization
}

\author{
Seyed Mohammad Dadgaran ${ }^{a}$, Ali Akbar Farhangi ${ }^{a}$, Reza Najafbeigi ${ }^{a}$ and Roghiyeh Jame ${ }^{b^{*}}$
}

${ }^{a}$ Department of Management, Science and Research Branch, Islamic Azad University, Tehran, Iran

${ }^{b} \mathrm{PhD}$ student in Media Management, Department of Management, Science and Research Branch, Islamic Azad University, Tehran, Iran

\section{H R O N I C L E}

Article history:

Received July 2, 2012

Received in revised format

28 October 2012

Accepted 11 November 2012

Available online

November 142012

Keywords:

Privatization

Media privatization

TV media

\section{A B S T R A C T}

During the past few years, there has been growing interests in reducing cost of products and services among developing countries. Privatization is believed to be one of the most important techniques to increase relative efficiencies of publically held organizations. In this paper, we study important barriers on privatization of television (TV) media industry in Iran. The proposed study of this paper designs and distributes a questionnaire using a sample of 234 out of 600 graduate students who were enrolled in media communication studies and examined six hypotheses based on one-side t-student. The survey considers different factors influencing privatization of TV media industry. The results of the investigation indicate that the cost of TV production, short and long-term investment security, people's interest on investing on TV media industry, building appropriate culture, cultural obstacles and economic barriers influence media privatization, significantly.

\section{Introduction}

Media plays an important role on building a bridge between people and government, industry and society. It is an important part of people's lives and many prefer to spend some important time on following news, entertainment, etc. Television media (TV) is, on the other hand, a significant component of governments to express their best interests. Privatization plays an important role on reducing cost of TV media but going private for this industry is not as easy as other industries and we need to perform appropriate action plans. Therefore, we need to study the effects of privatization in other countries. During the last two decades, many countries have launched extensive privatization programs and there is a growing body of literature on the effect of privatization on productive efficiency (Oktan, 2006).

Sprenger (2011) found that the transformation of ownership of productive asserts from state and private ownership has been one of the most important and, at the same time, most controversial

*Corresponding author. Tel: +989121726884

E-mail addresses: jame_ir29@yahoo.com (R. Jame) 
aspects of the transition of the former socialist economics to market economics. Privatization was launched in the countries of central and Eastern Europe, the former Soviet Union and China to promote enterprise restructuring with the ultimate goal to improve the operating performance of enterprises. A vast majority of the empirical studies has found positive effects of privatization on indicators of performance and restructuring on average.

However, the success of large-scale privatization in the transition process is far from being uniform across countries in terms of methods, ownerships of privatized companies. Brown et al. (2006) found that the effect of privatization on productivity is significant and positive in Hungary and Romania but, small or even negative in Ukraine and Russia. Only privatization by foreign investors had significant and positive effects in all four countries under investigation. Several studies have shown that company outsiders. In addition, ownership concentration has been found to be conductive to better performance in several studies (e.g., Hanousek et al., 2007). In US, public services contracted out to private providers sometimes ended up saving (Avant, 2005). Yarrow et al. (1986) investigated the theoretical and empirical case for public versus private ownership. Privatization usually helps managers put bigger emphasis on the pursuit of profits but many people argued whether this was beneficial to society depending on the trade-off between possible market failures, which happens because of lack of competition in government control of public firms. The competitive and regulatory environment plays an important role in many industries. In competitive markets, private ownership is getting more popularity but when there is a natural monopoly, some regulatory action is necessary. There are some evidences suggesting that privatization had led to improved performance by firms such as the National Freight Corporation and Cable and Wireless which operate in a competitive environment. Privatization is also advanced as a tool to reduce trade union power, encouraging wider share ownership, redistributing wealth and improving the public finances. However, there are other policy tools better suited for reaching appropriate objectives.

Hearn et al. (2009), for instance, offered a comprehensive and in-depth academic overview of the application of action research methods to the field of new media. Katz (2005) discussed media policy for the $21^{\text {st }}$ century in the United States and Western Europe. Servaes and Wang (1997) discussed privatization and commercialization of the Western-European and South-East Asian broadcasting media. Nellis (1999) also argued that we should reconsider privatization in transition economies. Karamanis (2003) in another survey investigated the role of culture and political institutions in media policy for the case of TV privatization in Greece. During the past few years, U.S. public television, an ostensibly noncommercial system built on public service principles, has been increasingly integrated into the commercial broadcasting sector.

Hoynes (2003) investigated the new, market-oriented business practices within American public television, which concentrate the constructing of brand identity. Over the past two decades, the Public Broadcasting Service (PBS) has sought to extend its brand beyond broadcast television and cash in on consumer loyalty to PBS. This branding strategy chooses an audience of consumers, and it sells both "content" and an image to these consumers. This is a primary component of a broader strategy focused at leveraging the PBS brand to build new revenue streams by licensing the PBS logo, selling new forms of advertising, and developing several PBS brand name product lines. He explored the consequences of the brand-building approach for the future of public service broadcasting. Kwak et al. (2002) performed a cross cultural study between the United States and South Korea by investigating the role of gender and compulsive buying tendencies in the cultivation effects of TV show and TV advertising. Onwumechili (1996) also investigated privatization on Nigerian media and discussed the advantage and disadvantage of privatization on this industry. The organization of this paper first presents details of our various hypotheses in section 2 while section 3 presents details of the findings of the investigation. Finally, concluding remarks are given in the last to summarize the contribution of the paper. 


\section{The proposed study}

The proposed study of this paper considers all graduate students who were enrolled in media and communication studies. Therefore, we use the following formula to calculate the minimum number of sample size,

$n=\frac{N \times z_{\alpha / 2}^{2} \times p \times q}{\varepsilon^{2} \times(N-1)+z_{\alpha / 2}^{2} \times p \times q}$,

where $N$ is the population size, $p=1-q$ represents the yes/no categories, $z_{\alpha / 2}$ is CDF of normal distribution and finally $\varepsilon$ is the error term. Since we have $p=0.5, z_{\alpha / 2}=1.96$ and $N=600$, the number of sample size is calculated as $n=234$.

The proposed study of this paper considers the following questions,

1. What are the main barriers on TV networks privatization?

2. How much does high cost of production influence TV privatization?

3. How much does the lack of security in short and long term private sector investment influence TV privatization?

4. How much does the lack of advertisement impact on TV privatization?

5. How much does the lack of cultural barriers impact on TV privatization?

Based on these questions and concerns, the following six hypotheses are investigated in this survey. Fig. 1 shows details the framework of the proposed study of this paper.

1. The cost of TV production impacts privatization of media.

2. Short and long-term investment security impact on media privatization.

3. People's interest on investing on TV media industry influences privatization.

4. Building appropriate culture influences media privatization.

5. Cultural obstacles impact media privatization.

6. Economic barriers influence media privatization.

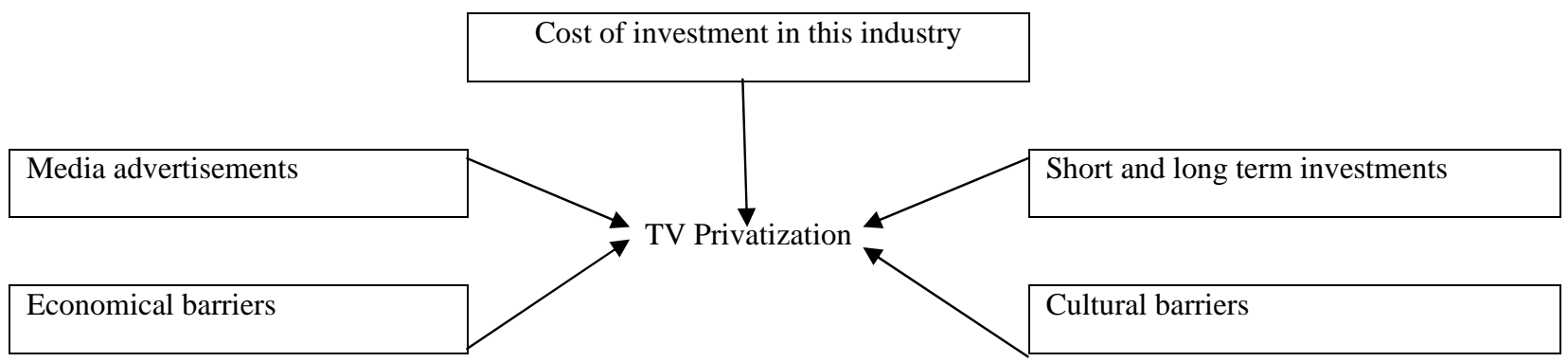

Fig. 1. The framework of the proposed study

\section{The results}

In this section, we present details of our findings on six hypotheses of this paper.

\subsection{The first hypothesis}

The first hypothesis of this survey is associated with the relationship between cost of establishing TV media and TV privatization. The following shows the proposed hypothesis of this paper,

$$
\left\{\begin{array}{l}
H_{0}: \mu=0.5901 \\
H_{1}: \mu \neq 0.5901
\end{array}\right.
$$


The results of t-student yields mean of 0.779405 with standard deviation of 0.3538088 , standard error mean of 0.0231292 and the results of one-sample test is as follows,

\section{Table 1}

The results of on-sample t-test on the first question (Test Value $=0.590163934$ )

\begin{tabular}{lllllll}
\hline & & & & & \multicolumn{2}{c}{ 95\% Confidence Interval of the Difference } \\
Question & $\mathrm{T}$ & $\mathrm{df}$ & Sig. (2-tailed) & Mean Difference & Lower & Upper \\
\hline Q1 & 8.182 & 233 & .000 & .1892412 & .143672 & .234810 \\
\hline
\end{tabular}

Based on the results of Table 1 we have,

$$
0.143672 \leq \bar{X}-\mu_{x} \leq 0.234810, \quad 0.143672 \leq 0.5901-\mu_{x} \leq 0.234810,0.733836 \leq \mu_{x} \leq 0.824974
$$

The results of our survey indicate that we can reject the null hypothesis when the level of significance is five percent and conclude that the cost of establishing TV media impacts TV privatization, significantly.

\subsection{The second hypothesis}

The second hypothesis of this survey is associated with the relationship between short and long term investment of establishing TV media and TV privatization. The results of t-student yields mean of 0.939174 with standard deviation of 0.1852469 , standard error mean of 0.0121100 and the results of one-sample test is summarized in Table 2 as follows,

\section{Table 2}

The results of on-sample t-test on the second question of the survey (Test Value $=0.590163934$ )

\begin{tabular}{lllllll}
\hline & & & & & \multicolumn{2}{c}{ 95\% Confidence Interval of the Difference } \\
Question & $\mathrm{T}$ & $\mathrm{df}$ & Sig. (2-tailed) & Mean Difference & Lower & Upper \\
\hline Q2 & 28.820 & 233 & .000 & .3490105 & .325151 & .372869 \\
\hline
\end{tabular}

The results of testing the second hypothesis indicate that we can reject the null hypothesis when the level of significance is five percent and conclude that short and long term investment impacts on establishing TV media impacts TV privatization, significantly.

\subsection{The third hypothesis}

The third hypothesis of this survey is associated with the relationship between People's interests on investing on TV media industry influences privatization. The results of t-student yields mean of 0.652131 with standard deviation of 0.3730643 , standard error mean of 0.0243880 and the results of one-sample test is summarized in Table 3 as follows,

\section{Table 3}

The results of on-sample t-test on the third question of the survey (Test Value $=0.590163934)$

\begin{tabular}{llllllc}
\hline & & & & & \multicolumn{2}{c}{ 95\% Confidence Interval of the Difference } \\
Question & T & df & Sig. (2-tailed) & Mean Difference & Lower & Upper \\
\hline Q3 & 2.541 & 233 & .012 & .0619673 & .013918 & .110016 \\
\hline
\end{tabular}

The results of testing the third hypothesis indicate that we can reject the null hypothesis when the level of significance is five percent and conclude that people's interests in investing in media industry influences on establishing TV media impacts TV privatization, significantly. 


\subsection{The fourth hypothesis}

The fourth hypothesis of this survey is associated with the relationship between building appropriate culture investment on TV media industry, which influences privatization. The results of t-student yields mean of 0.975467 with standard deviation of 0.1765629 , standard error mean of 0.0115423 and the results of one-sample test is summarized in Table 4 as follows,

\section{Table 4}

The results of on-sample t-test on the fourth question of the survey (Test Value $=0.590163934$ )

\begin{tabular}{lllllll}
\hline & & & & \multicolumn{2}{c}{ 95\% Confidence Interval of the Difference } \\
Question & $\mathrm{T}$ & $\mathrm{df}$ & Sig. (2-tailed) & Mean Difference & Lower & Upper \\
\hline Q4 & 33.382 & 233 & .000 & .3853031 & .362563 & .408044 \\
\hline
\end{tabular}

The results of testing the fourth hypothesis indicate that we can reject the null hypothesis when the level of significance is one percent and we can conclude that building appropriate culture on investing in media industry influences on establishing TV media and impacts TV privatization, significantly.

\subsection{The fifth hypothesis}

The fifth hypothesis of this survey is associated with the relationship between cultural obstacles on investment on TV media industry and TV privatization. The results of t-student yields mean of 0.603488 with standard deviation of 0.4357692 , standard error mean of 0.0284871 and the results of one-sample test is summarized in Table 5 as follows,

\section{Table 5}

The results of on-sample t-test on the fifth question of the survey (Test Value $=0.590163934$ )

\begin{tabular}{lllllll}
\hline & & & & \multicolumn{2}{c}{ 95\% Confidence Interval of the Difference } \\
Question & $\mathrm{T}$ & $\mathrm{df}$ & Sig. (2-tailed) & Mean Difference & Lower & Upper \\
\hline Q5 & 45.839 & 233 & .000 & .4166544 & .398746 & .434563 \\
\hline
\end{tabular}

The results of testing the fifth hypothesis indicate that we can reject the null hypothesis when the level of significance is one percent and conclude that cultural barriers on investing in media industry influences on establishing TV media and impacts TV privatization, significantly.

\subsection{The sixth hypothesis}

The sixth hypothesis of this survey is associated with the relationship between economic barriers on investment on TV media industry and TV privatization. Table 6 shows details of our t-test on this hypothesis.

\section{Table 6}

The results of on-sample t-test on the sixth question of the survey (Test Value $=0.590163934)$ 95\% Confidence Interval of the Difference

\begin{tabular}{lllllll} 
Question & T & df & Sig. (2-tailed) & Mean Difference & Lower & Upper \\
\hline Q6 & 10.605 & 233 & .000 & .2198581 & .179015 & .260701 \\
\hline
\end{tabular}

The results of testing the sixth hypothesis indicate that we can reject the null hypothesis when the level of significance is one percent and conclude that economical barriers on investing in media industry influences on establishing TV media and impacts TV privatization, significantly.

It is necessary to note that governmental system of proposed case study of this paper is based on religion and TV must honor Islamic values in all its channels. Therefore, the people who run these 
channels must comply with rules and regulations of the country. In such circumstances, any privatization must be executed very carefully.

\section{Conclusion}

In this paper, we have performed an empirical investigation to find out the most important barriers in implementing privatization in media industry. The proposed study of this paper designed a questionnaire and distributed among graduate students who were enrolled in media communication. The results of this survey has revealed that the cost of TV production, short and long-term investment security, people's interest on investing on TV media industry, building appropriate culture, cultural obstacles and economic barriers influence media privatization, significantly.

\section{Acknowledgment}

The authors would like to thank the anonymous referees for constructive comments on earlier version of this work, which have significantly contributed to quality of the paper.

\section{References}

Avant, D. (2005). The market for force. Cambridge: Cambridge university press.

Brown, J. D., Earle, J. S., \& Telegdy. A. (2006). The productivity effects of privatization: Longitudinal estimates from Hungary, Romania, Russia. Ukraine Journal of political Economy, 114, 61-99.

Hearn, G.N., Tacchi, J.A., Foth, M., \& Lennie, J. (2009). Action Research and New Media: Concepts, Methods and Cases. Hampton Press, Cresskill, NJ.

Hoynes, W. (2003). Branding Public Service The" New PBS" and the Privatization of Public Television. Television \& new media, 4(2), 117-130.

Hukill, M. A. (1994). The privatization of television in Singapore. AMIC Seminar on Television Development in the Asia-Pacific Region, Jakarta, Dec 8-9.

Hanousek, J., Kocenda, E., \& Svejnar, J. (2007) Origin and concentration -corporate ownership, control and performance in firms after privatization. Economics of Transition, 15, 1-31.

Katz, Y. (2005). Media policy for the 21st century in the United States and Western Europe. Hampton Pr.

Karamanis, T. (2003). The role of culture and political institutions in media policy: The case of TV privatization in Greece (New media: Policy and research issues).

Kwak, H., Zinkhan, G. M., \& Dominick, J. R. (2002). The moderating role of gender and compulsive buying tendencies in the cultivation effects of TV show and TV advertising: A cross cultural study between the United States and South Korea. Media Psychology, 4(1), 77-111.

Nellis, J. R. (1999). Time to rethink privatization in transition economies? (No. 38). World Bank Publications.

Onwumechili, C. (1996). Privatization of the electronic media in Nigeria. Howard Journal of Communications, 7(4), 365-372.

Oktan, G ., \& Peren, A.K. (2006). The effects of privatization on Efficiency: How does privatization works? World Development, 34(9), 1537-1556.

Sprenger, C. (2011). The choice of ownership structure: Evidence from Russia Mass privatization. Journal of comparative economics, 39(2), 260-277.

Servaes, J., \& Wang, G. (1997). Privatization and commercialization of the Western-European and South-East Asian broadcasting media. Asian Journal of Communication, 7(2), 1-11.

Yarrow, G., King, M., Mairesse, J., \& Melitz, J. (1986). Privatization in theory and practice. Economic policy, 324-377. 